\title{
The Fire Risk of Cigarette Factory and Research on Design Technology of Fire Protection System
}

\section{Tiande Luo}

male, 1975 , engineer, graduated from South China University of Technology, worked in the tobacco industry in Guangdong, research direction, Tobacco companies fire safety technology.

\section{Zi ying Liang}

male, 1963 , engineer, worked in the tobacco industry in Guangdong, research direction, Tobacco companies fire safety technology.

\begin{abstract}
Cigarette and tobacco production plant is an important place for storage, you need to set up safe and reliable fire protection systems in order to cope with all kinds of unexpected fires. This paper focuses on the joint Kobo cigarette factory, power plant, experimental studio, deployment center, library and finished products such as flavors and fragrances manufacturing and warehouse storage areas and causes a fire hazard, and the actual operation of the system through the fire management process for each system problems encountered, suggestions cigarette factory fire system design.
\end{abstract}

KEYWORD: Tobacco; Fire risk; Complex production workshop; Stores; Fire equipment

\section{INTRODUCTION}

Our country is the largest country in the world tobacco consumption. 2013 full-year industry realized profits and taxes 955.986 billion yuan, 91.047 billion yuan more than 2012 new, up 10.53\%; which taxes (excluding corporate income tax) 681.061 billion yuan, an increase of 59.871 billion yuan, an increase of 9.64 percent. The annual total 816.122 billion yuan turned over to finance, added nearly 100 billion yuan, up 13.9 percent; which 29.568 billion yuan turned over to the state capital gains, after-tax profit of 40 billion yuan turned over to the special, financial income for the country to make a special contribution. [1] Tobacco has become an important force in China's national economic development. Tobacco industry as an important source of state revenue. In recent years, a new round of tobacco work offsite technical innovation, technological inputs is relatively large, the production and operation of buildings and equipment for the tobacco production process are relatively expensive, so tobacco unemployed tobacco fire safety is especially important to do.

In recent years, technological innovation is most cigarette factory in accordance with the company's large foreign tobacco production, storage mode, combined with automated systems, such as production equipment, the cigarette factory designed in the form of joint production studio, that the processing line, expanded tobacco line, cigarette envelope, elevated library,including raw materials libraries, library, libraries, and finished products recipes, and other plants use a combination of a variety of functions in the same building and conjoined buildings, in order to achieve continuous production, material handling short distance and the purpose of centralized management $。$ The relevant independent power center power centers, experimental studio, deployment center, library and other flavors and spices of the electricity, compressed air, steam, air conditioning and other utility services through an underground pipeline network to the joint production studio, experimental studio production sites and finished products, etc.

Whether each cigarette factory itself or public buildings boilers, compressed air machines, air conditioners and other facilities and equipment, whether it is equipment worth Hood production equipment ,such as one on the M8 machine billion yuan, was used to detect the experiment are very expensive, with a daily turnover of finished tobacco store finished products are 100 million yuan. Preliminary estimates, the entire cigarette factory assets reached hundreds of billion yuan.

So, do the cigarette factory fire safety management work is the key to the key. I had the honor to participate in the technological transformation cigarette factory, the management of the fire protection system running directly after completion, these are good fire safety work has accumulated some experience. The author analyzes the cigarette factory joint production studio, power centers, experimental studio, deployment center, library and finished products such as flavors and fragrances fire hazard and made a cigarette factory 
building fire safety design recommendations apply to the operation of the fire protection system in accordance with the current problem.

\section{CIGARETTE FACTORY FIRE HAZARD ANALYSIS}

\subsection{Tobacco is a Class C flammable solid.}

According to "architectural design code for fire protection" (hereinafter referred to as "Building Regulations"), and "high-rise building fire protection design" [2] [3] [4] (hereinafter referred to as "high regulation") requirements, Tobacco store fire hazard characterization for the Class $\mathrm{C}$ in "combustible solids", lighted tobacco is $220^{\circ} \mathrm{C}$, the main manifestations of the phenomenon of spontaneous combustion burning, smoldering, fire these three forms. There can lead to smoldering flame burning, it's burning into the source of fire burning and spontaneous combustion (no ignition sources). Principle of spontaneous combustion spontaneous combustion of tobacco and other substances, like: Tobacco itself is self-heating, heat is generated when the temperature is greater than the heat loss to the ignition point, and then occur naturally.

\subsection{Other reasons can lead to burning tobacco.}

Paper production and operation of tobacco used, tow, cigarette trademarks, cigarette waterproof wrapping paper, cardboard boxes, linen sheet and other accessories fire hazard, cardboard boxes, etc. are flammable, combustible, thermal decomposition temperature, spontaneous combustion points are relatively low. Ignition is generally carton $130{ }^{\circ} \mathrm{C}$, combustible solid heat can break down, and its thermal decomposition temperature (ie, the initial temperature of the heat decomposition occurs), ignition point (when heated to a certain extent can automatically burn the lowest temperature) is a fire risk assessment one of the main parameters. The lower the thermal decomposition temperature, the lower the ignition, combustion faster, the greater the risk of fire; the lower the ignition point, the greater the tendency to burn, the greater the risk of fire.

\subsection{Produced a kind of electrical fire hazards}

Tobacco Factory production of a large amount of electrical equipment, electrical equipment when the work overload will cause short circuit, arc, spark, spark ignited the existence of tobacco, accessories carton cardboard, ceiling grid and fiber optic cable twisted pair cable, such as a fire hazard sex is one of the most important fire hazard. According to statistics, the fire occurred due to an electrical fire caused more than $80 \%$.

\subsection{Fire hazard may occur when tobacco fumigation and spraying to kill pests}

Cigarette factory every year to pests silk, cigarette packages and experimental line production line process of fumigation and spraying treatment. The use of aluminum phosphide fumigation and spraying, when aluminum phosphide case of acid or water and moisture, and can react violently, spontaneous combustion can emit toxic phosphine gas. Phosphine can effectively inhibit and kill microorganisms, to prevent tobacco mildew. But it is flammable, toxic, odor with acetylene. When the air reaches a certain concentration of phosphine, will spontaneous combustion and detonation; when the temperature exceeds $60^{\circ} \mathrm{C}$, immediately spontaneous combustion in air can react with oxidants, cause a fire or explosion, fire more dangerous.

\subsection{When a potentially explosive gas leak fire hazards}

Current cigarette factory boiler room, expanded tobacco puffing end, HTD hot end, kitchen and other places have to use a unified municipal gas supply, and as production increases, the amount of naturally increased. Received from the municipal supply pipe factory skid station, factory or building by an underground natural gas pipeline grid interspersed each use to end. Pipeline leak and use client has the possibility of an explosion caused a fire hazard prone.

\subsection{Ming fire ignition sources external fire hazards}

Most new cigarette factory covers an area of technological transformation in recent years, a large, construction of the plant species to reach hundreds of thousands of square meters, the new plant due to the design and technical innovation of the actual use of the process there are some places will not need a third-party service, please units of buildings and production equipment to improve maintenance, repair process requires a temporary hot work, each year after the author's temporary hot work permit approval of thousands of copies, and leave the rest of the job, such as protective measures and monitoring done enough good, it is easy to cause a fire hazard. On the other hand, foreign workers out of the workshop, finished area who are many and complex, there are a small number of personnel to carry fire approach, there is a fire hazard. 


\section{CIGARETTE FACTORY BUILDING FIRE CASE}

\subsection{Each building meets fire resistance rating "Building Regulations", "high regulation" and "cigarette factory design specifications" of relevant requirements.}

Each production plant and warehouse buildings Cigarette Factory, Beijing Wuzhou institute strict accordance with "Building Regulations" specification requirements: Class $\mathrm{C}$ fire rating as a secondary fire resistance rating of building design, construction units by drawing facilities and acceptance. Where the author is in a cigarette factory of reinforced concrete joint production studio, elevated library, power centers, or through steel and other structural fire retardant paint by treatment composition, part of the office and production auxiliary room interior decoration materials, mostly resistance, flame retardant materials, fire resistance of building elements of its relatively high. The Fire design studio by the Joint Research Center of the National Technical Advisory Department fire engineering safety assessment review, Guangdong Province Public Security Fire experts specialized organizations related to "Building Regulations" Management Group, research, design and demonstrate the formation of public security "in Guangdong tobacco industry Company production base in Guangzhou joint Kobo Fire Safety analysis Report".[2]

\subsection{Fire protection system more perfect}

Cigarette factory joint production studio, fire systems power center, elevated library, technology lab and other buildings are: the main air sampling alarm system alarms, smoke (temperature) sense of alarm, infrared alarm on the radio, manual alarm, combustible gas concentration alarm and other systems; fire extinguishing system are: automatic sprinkler, water mist, electronically controlled rain shower, Bing alkyl sevoflurane gas, foam fire extinguishing and fire hydrants and other emergency broadcasting system, smoke control systems, video surveillance systems. there are fire extinguishers, and other fire-mouth filter respirator. These firefighting facilities and fire protection products for the cigarette factory production, storage provides a reliable fire safety and security, even if a fire occurs, it can detect and extinguish fires in the early and reduce losses.

\section{MANAGEMENT STATUS CIGARETTE FACTORY FIRE}

\subsection{There are specialized fire-fighting facilities Maintenance Unit}

In strict accordance with the requirements of
Municipal Public Security Fire, good fire box standardization and household management work, repair and maintenance units every month to do Maintenance and fill in the relevant records, records uploaded standardized management system. Ensure that the fire system is in normal operation.

\subsection{Has a volunteer fire department}

Led by the security department, and the remaining members of the department staff and security organizations volunteer fire department, volunteer team to carry out the required training to learn and operate real guarantee when fire emergency can be pulled out of the initial fire fighting.

\subsection{Fire administrators to configure foot}

Tobacco Factory in addition to the security sector with two full-time fire administrator, etc. In addition, the focus of the workshop and warehouse department, complete with a part-time member of the fire safety, fire safety work is carried out smoothly to provide a strong guarantee. All personnel must warehouses which are part-time team volunteer firefighters, emergency support which enhances the power of the warehouse. Each is equipped with a fire control officer on duty monitoring, supervisor sure to attend City Police Fire training qualified job card, various sets of fire fighting equipment and emergency response systems are familiar with the process plant operation, problems can be the first disposal.

\subsection{Maintaining a fire emergency drills}

According to standardized requirements, annual plant level is at least two emergency firefighting drills, departmental organization explosion fire evacuation emergency evacuation drills according to the situation of each team, thus improving everyone's emergency management capabilities.

\subsection{As the focus of the regulatory unit City Fire Department.}

Tobacco Factory in strict accordance with the city's fire management standardization required to complete compliance, adhere to fire safety inspections do related work, such as the control room duty every day. And provides a demonstration role and window factories City Fire Department Fire-intensive enterprises and household registration management standardization work. Fire management has been the focus of attention of City Fire Department, and accept the supervision and guidance, to promote the implementation of fire safety management work, forming a good interactive situation. 


\section{FIRE PROTECTION SYSTEM PROBLEMS ENCOUNTERED DURING OPERATION}

\section{1 issues 1}

When power center space with laminated between two B steam room due to higher temperatures, higher non-addressable thermal detectors (especially the steam pipe above the detector) false alarm rate, turn the main automatic alarm system host state, often cause linkage, affecting production.

\subsection{Issues 2}

The cigarette factory canteen feeling cold and catering area smoke detectors, heat detectors food processing, air conditioner and steam affected often report false alarms, causing linkage, cut non (power outage, off the air conditioner, start exhaust fan, etc.), affecting the normal operation of the plant.

\subsection{Issues 3}

Room expansion joint production workers infrared detectors loose tobacco shop floor control between carbon dioxide, when due to equipment maintenance and cleaning personnel and air conditioner cover the layer appears in the control room, often alarm, causing the linkage, the impact of expanded tobacco normal production.

\subsection{Issues 4}

Joint production plant technology production equipment, often among the washing, wash chain row between steam cleaning, the room temperature detector will often false alarms, causing linkage, the linkage affecting the normal production.

\section{COUNTERMEASURES FIRE SYSTEM RUNNING PROBLEMS}

According to the new Automatic Fire Alarm Code: "automatic fire alarm system design"[2], On May 1, 2014 the formal implementation. We re-optimized design and completion of corrective actions in accordance with the new requirements of this specification. Ensure that these problems from happening again.

\subsection{Proposal 1}

Laminated between two power centers B empty room with gas due to high temperatures,

it is recommended to install eight Nomi is now 60 degrees actions addressing non-differential temperature thermal detectors to higher operating temperature type or non-addressable detectors .

\subsection{Proposal 2}

Canteen cancel within the recommended cold probe, the cold smoke detector outside the corridor to move 2-3 meters of cold storage in the opposite direction, catering area smoke detectors, heat detectors food processing proposal to change the temperature difference between the temperature type detectors (of six).

\subsection{Proposal 3}

Kobo expansion joint production between carbon dioxide loose tobacco shop floor infrared detectors on the radio,

\subsection{Proposal 4}

Between washing, wash chain row between the actual operation of thermal detectors high rate of false positives, it is recommended to differential temperature type heat detectors.

\section{CONCLUSION}

In this paper, through the various cigarette factory building fire risk is analyzed, and the problems encountered during the operation of the fire protection system, proposed solutions, which optimize production safety improvement program to reduce unnecessary trouble, but also greatly reduce a tobacco factory production process impacts and losses. In the future, a sister unit to attach importance to these technological transformation process in the Tobacco Factory Fire design needs. In short, the tobacco factory only from a technical and management aspects pronged approach in order to effectively reduce the incidence of and avoid casualties and significant property damage heavy cigarette factory fire accident, the tobacco industry has played an active role in production safety.

\section{REFERENCES}

[1] Report of the Secretary LingChengxing State Tobacco Monopoly in 2014 National Conference on Tobacco. 2014.1

[2] "Tobacco Industry Company, Guangzhou, Guangdong production base in the United Kobo Fire Safety Analysis Report”. 2008.3.

[3] GB50016-2006, Architectural design code for fire protection.

[4] GB50045-95-2005 "Fire protection design of tall buildings".

[5] YC0009-04. "Cigarette Factory Design Specification" revision.

[6] “Automatic fire alarm system design” GB50116-2013. 